\title{
Hospedabilidade de genótipo de cebola ao Meloydogyne javanica e Pratylenchus brachyurus
}

\author{
Onion genotype hospitability to Meloydogyne javanica and \\ Pratylenchus brachyurus
}

\author{
Natália Regina de Campos NÓIA2; Antônio Jesus PERONI ${ }^{1 ; 3}$; Marcelo Jara DAVALO ${ }^{4}$; \\ Paulo Roberto Pala MARTINELLI ${ }^{5}$
}

1 Este trabalho é parte da monografia do segundo autor.

2 Engenheira Agrônoma, Mestranda. Departamento de Solos e Adubos, Universidade Estadual Paulista, Campus de Jaboticabal, Via de Acesso Prof. Paulo Donato Castellane s/n - 14884-900 - Jaboticabal, SP. natalia_campos_17@hotmail.com, (16) 98202-0172 (autora para correspondência).

${ }^{3}$ Engenheiro Agrônomo. Instituto Taquaritinguense de Ensino Superior, Praça Dr. Horácio Ramalho, 159 - Centro Taquaritinga/SP. antonio-peroni@hotmail.com

${ }^{4}$ Mestre em Agronomia, Doutorando. Departamento de Solos e Adubos, Universidade Estadual Paulista, Campus de Jaboticabal, Via de Acesso Prof. Paulo Donato Castellane s/n 14884-900 - Jaboticabal, SP. jara_davalo@hotmail.com

${ }^{5}$ Docente, Doutor. Departamento de Fitossanidade, Universidade Estadual Paulista, Campus de Jaboticabal, Via de Acesso Prof. Paulo Donato Castellane s/n 14884-900 - Jaboticabal, SP.prpmartinelli@yahoo.com.br

Recebido em: 10-12-2014; Aceito em: 29-05-2016

\section{Resumo}

O objetivo da pesquisa foi avaliar a hospedabilidade de cinco cultivares de cebola aos nematoides do gênero Meloidogyne javanica e ao Pratylenchus brachyurus. Foram realizados dois ensaios no campo experimental do ITES- Taquaritinga- SP, as variedades de cebola cultivadas foram Superex, Express, Luana, Sírius e Aquarius e duas culturas-teste (berinjela e milho). O delineamento experimental foi o inteiramente casualizado (DIC), com seis repetições cada experimento. Após 20 dias da emergência das plântulas, o primeiro ensaio foi inoculado com a suspensão de ovos e juvenis de segundo estádio (J2) do nematóide Meloidogyne javanica (1.652 indivíduos por $\mathrm{mL}$ ), e o segundo ensaio, com Pratylenchus brachyurus (2.300 indivíduos por $\mathrm{mL}$ ) em cada vaso. Aos 120 dias após a inoculação, as raízes foram retidas dos vasos e enviadas ao laboratório para a determinação da população inicial, matéria fresca do sistema radicular, população final, fator de reprodução, resistência e suscetibilidade. Os dados obtidos foram submetidos à análise de variância, e as médias significativas foram submetidas ao teste de Duncan, a $5 \%$ de probabilidade. As cinco variedades de cebola estudadas $\mathrm{e}$ as culturas-teste (berinjela e milho) apresentaram fator de reprodução inferior $<1$, demonstrando-se resistentes ao ataque dos gêneros Meloidogyne javanica e Pratylenchus brachyurus.

Palavras-chave adicionais: Allium cepa; inoculo; nematoide; resistência; variedades.

\begin{abstract}
The objective of the research was to evaluate the Host status five onion cultivars to Meloidogyne javanica nematodes of the genus Pratylenchus and brachyurus. Two experiments were carried out in experimental ITES- Taquaritinga - SP field, the varieties of onions were grown (Superex, Express, Luana, Sirius and Aquarius) and two cultures test (eggplant and corn). The experimental design was completely randomized (DIC) with six replicates each experiment. After 20 days of seedling emergence, the first test was inoculated with the suspension of eggs and second stage juveniles (J2) of Meloidogyne javanica (1652 individuals per ml), and the second test with Pratylenchus brachyurus (2300 individuals per $\mathrm{ml}$ ) in each pot. At 120 days after inoculation, the roots were retained vessel and sent to the laboratory to determine the initial population, fresh weight of the root system, final population, reproduction factor, resistance and susceptibility. The data were submitted to analysis of variance and significant means were submitted to Duncan test at $5 \%$ probability. The five varieties studied onions and test crops (eggplant and corn) had lower reproduction factor $<1$, showing to be resistant to attack by Meloidogyne javanica genres and Pratylenchus brachyurus.
\end{abstract}

Additional keywords: Allium cepa; inoculum; nematode; resistance; varieties.

\section{Introdução}

A cebola é uma espécie bienal, tendo a formação de bulbos no primeiro ciclo e a formação de sementes no ciclo subsequente, através do plantio de bulbos. A simplificada arquitetura da parte aérea da planta de cebola faz com que diferentes patógenos e pragas venham causar sintomas semelhantes e, muitas vezes, indistintos de causas abióticas, como déficit hídrico, desequilíbrio nutricional, fitotoxidade, entre outros (Wordell Filho, 2006).

Frente a isto, muitas vezes, os problemas 
que afetam a cultura da cebola são diagnosticados erroneamente. Como consequência, observa-se o uso frequente de defensivos agrícolas ao invés de um manejo integrado para o controle e o combate de pragas e doenças (Wordell Filho, 2006).

Perdas agrícolas ligadas ao ataque de nematoides variam muito de uma cultura para outra, tendose que levar em consideração a espécie de nematoide e a cultura hospedeira envolvida. Segundo estimativas, as perdas por injúrias de nematoides são em média de 5 a $35 \%$ para diferentes culturas no Brasil (Castro Neto \& Toscano, 2014).

$\mathrm{Na}$ cultura da cebola, é possível encontrar várias espécies de parasitas de raíz e coroa, entre as quais têm-se: Longidorus caespiticola, Belonolaimus longicaudatus, Paratrichodorus minor, Xiphinema diversicaudatum, Rotylenchus reniformes, Meloidogyne spp., Pratylenchus spp. E Ditylenchus dipsaci (Green \& Atkinson, 2005). Os nematoides do gênero Meloidogyne spp. atacam o sistema radicular das plantas, provocando pequenas galhas, reduzindo o crescimento da parte área e das raízes, e causando o amarelecimento de folhas e bulbos alongados (Wordell Filho, 2006).

O gênero Pratylenchus spp. é um endoparasita migrador (Ritzinger \& Costa, 2004). Este gênero é responsável por causar lesões nas raízes, pois elas cavam túneis pelo córtez radicular. Nesta espécie, todos os estágios, exceto os ovos, são livres e podem parasitar as raízes (Nazareno, 2009). Diante disto, o objetivo da pesquisa foi avaliar a hospedabilidade de cinco cultivares de cebola ao Meloidogyne javanica e Pratylenchus brachyurus.

\section{Material e métodos}

O experimento foi conduzido no campo experimental do ITES - Taquaritinga - SP, localizado na latitude $21^{\prime} 25^{\prime} 01$ 'S, longitude 48 '30'07W e altitude de 512,30 metros. Foram montados dois ensaios em vasos com cinco cultivares de cebola (superex, express, Luana, sírius e aquarius) e, para o ensaio com Meloydogyne javanica, foi utilizada como cultura-teste a berinjela, e para Pratylenchus brachyurus, o milho.

As semeaduras foram realizadas em 25 de março de 2013, em vasos de plástico com capacidade para 5 litros, contendo substrato com uma mistura de areia grossa, esterco bovino e vermiculita, mais areia fina (sem autoclavar), na proporção de 1:1. O delineamento experimental foi o inteiramente casualizado (DIC), com 6 repetições, constituídas por um vaso cada (em cada vaso foram plantadas 10 sementes e após a emergência foram deixadas apenas 5 plantas por vaso). O preparado do inóculo ocorreu no Laboratório de Nematologia da FCAV/UNESP, seguindo-se a técnica descrita por Huney \& Barker (1973), e a contagem de ovos e juvenis de segundo estádio (J2) foi realizada em câmara de contagem de Peters, com o auxílio de microscópio fotônico. A população inicial de
Meloydogyne javanica foi extraída das raízes de tomateiro (Solanum lycopersicum L.). A suspensão de nematoide que constitui o inoculo foi ajustada para $165 \mathrm{~J} 2$ e ovos $/ \mathrm{mL}$.

A população inicial de Pratylenchus brachyurus foi extraída das raízes de soja (Glycine max [Merril]). Para o preparado do inoculo, seguiu-se a técnica descrita anteriormente para Meloydogyne javanica. A suspensão do nematoide, que constituiu o inóculo, foi ajustada para 200 ovos e J2 por mL.

A inoculação ocorreu 20 dias após a emergência das plântulas. Foram incorporados $10 \mathrm{~mL}$ da suspensão em cada sistema radicular. Assim resultando numa população inicial $(\mathrm{PI})$ de $1.650 \mathrm{M}$. javanica por vaso e de 2.000 para $P$. brachyurus por vaso.

As plantas foram mantidas em bancada suspensa, realizando-se irrigações diárias e, após 120 dias, foram realizadas as avaliações. Ao final do ensaio, as raízes das plantas foram coletadas e levadas ao laboratório, onde foram realizadas as extrações dos nematoides das raízes pela técnica de Coolen \& D'hererde (1972), e as contagens foram efetuadas nas suspensões com auxílio da câmara de contagem de Peters (Southey, 1970) ao microscópio fotônico, para a determinação da população final (Pf).

Em seguida, foi calculado o fator de reprodução (FR), que é definido pela relação $\mathrm{Pf} / \mathrm{Pi}$ (Oostenbrink, 1966). Plantas com FR $<1$ são consideradas resistentes e, portanto, não são hospedeiras favoráveis ao nematoide, enquanto as que exibem FR > 1 são suscetíveis, logo são hospedeiras favoráveis ao nematoide.

Os dados dos fatores foram submetidos à análise de variância e, quando significativas, as médias foram comparadas pelo teste de Duncan, a $5 \%$ de probabilidade, com auxílio de software Assistat 7.5 (Silva \& Azevedo, 2009).

\section{Resultados e discussão}

Nota-se que as cultivares de cebola e a cultura-teste (berinjela) se mostraram resistentes à hospedabilidade do Meloidogyne javanica (Tabela 1). Observa-se, ainda, diferença significativa para matéria fresca do sistema radicular, exceto para as variedades Aquarius e Luana; entretanto, não houve resultados significativos para população final de nematoides entre as variedades Aquarius, Sirius, Express e a culturateste.

Geralmente, as galhas de Meloidogyne na cultura da berinjela são bem menores em comparação com galhas em outras hortaliças, como, por exemplo, o tomateiro (Pinheiro et al., 2013). O M. javanica está entre as principais espécies de nematoides encontradas em áreas destinadas à produção de olerícolas (Rosa et al., 2013). Entre as culturas mais suscetíveis, encontram-se: quiabo, tomate, abóbora, batata e berinjela (Huang, 1992; Rosa et al., 2013).

Os nematoides do gênero Meloidogyne spp. 
atacam o sistema radicular e provocam pequenas galhas, reduzindo o crescimento das raízes e, consequentemente, causando redução da parte aérea das plantas (Wordell Filho, 2006). Isto explicaria a variação de massa fresca de raízes entre as cultivares testadas.

Tabela 1 - Reação de cultivares de cebola quanto à resistência aos nematoides das galhas Meloidogyne javanica.

\begin{tabular}{lccccc}
\hline Tratamentos & PI & PF & MFSR & FR & REAÇÃO \\
\hline Express & 1652 & $49,63 \mathrm{bc}$ & $19,95 \mathrm{ab}$ & 0,03 & $\mathrm{R}$ \\
Superex & 1652 & $18,23 \mathrm{c}$ & $7,61 \mathrm{~b}$ & 0,01 & $\mathrm{R}$ \\
Sirius & 1652 & $62,11 \mathrm{bc}$ & $25,00 \mathrm{ab}$ & 0,04 & $\mathrm{R}$ \\
Aquarius & 1652 & $131,98 \mathrm{ab}$ & $34,74 \mathrm{a}$ & 0,08 & $\mathrm{R}$ \\
Luana & 1652 & $188,37 \mathrm{a}$ & $32,82 \mathrm{a}$ & 0,11 & $\mathrm{R}$ \\
Berinjela (Testemunha) & 1652 & $96,49 \mathrm{ab}$ & $24,58 \mathrm{ab}$ & 0,06 & $\mathrm{R}$ \\
\hline Teste F (Tratamentos) & - & $3,37^{*}$ & $2,72^{*}$ & - & - \\
CV \% & - & 43,06 & 60,26 & - & - \\
\hline
\end{tabular}

Médias seguidas de mesma letra na coluna não diferem estatisticamente entre si, pelo teste de Duncan, a $5 \%$ de probabilidade. *Significativo a $5 \%$ de probabilidade; **significativo a $1 \%$ de probabilidade. Dados transformados em $\mathrm{X}+100$ para análise estatística dos dados. $\mathrm{PI}=$ população inicial de nematoides, MFSR = matéria fresca do sistema radicular; $\mathrm{PF}=$ população final; $F R$ = fator de reprodução; $R$ = resistente, e $S$ = suscetível.

Ao amostrar as raízes da cultura da banana, Pereira (2006) ressalta que houve maior frequência do Meloidogyne em relação aos outros gêneros presentes nas raízes, provavelmente, pela ampla gama de hospedeiros deste nematoide, o que favorece sua multiplicação, além de que, normalmente, inicia seu ciclo no solo a partir da massa de ovos depositada pela fêmea.

Os nematoides juvenis (J2) não se alimentam durante a fase de vida livre e utilizam os lipídios armazenados em seu intestino; no entanto, os juvenis liberam sinais químicos que estimulam as células do parênquima para se tornarem multinucleadas para que, mais tarde, os $\mathrm{J} 2$ se alimentem das células gigantes cerca de 24 horas após se tornarem sedentários (Guimarães, 2012).

Os danos causados por Meloidogye spp. variam de 3 a $5 \%$ na cultura da alface, de 5 a $7 \%$ em brócolis e de 1 a $5 \%$ na cultura da cebola (Rosa et al., 2013). No mercado, ainda não existem produtos registrados especificamente para o controle de nematoides na cultura da cebola. Tem-se recomen- dado a adoção de práticas culturais para evitar a disseminação e não realizar o cultivo em solos com histórico de ocorrência de nematoides (Gava \& Tavares, 2007).

Deve-se manter o cuidado com certificação de sementes e sanidades de mudas. Em áreas infestadas, deve-se optar pela rotação de culturas com plantas antagonistas, utilizar alqueive, eliminar os restos de cultura e plantas remanescentes (Pinheiro et al., 2014).

As cultivares de cebola e a cultura-teste (milho) mostram-se resistentes ao Pratylenchus brachyurus ao nível de $1 \%$ de probabilidade, pelo teste de Duncan (Tabela 2). A população final dos nematoides e a matéria fresca do sistema radicular não diferiram estatisticamente entre as variedades de cebola testadas. A determinação do número de nematoides por grama de raízes frescas é um parâmetro utilizado para se avaliar a população, pois este correlaciona-se diretamente com os prejuízos causados por nematoides (Fonseca, 2012).

Tabela 2. Reação de cultivares de cebola quanto à resistência aos nematoides das lesões radiculares Pratylenchus brachyurus.

\begin{tabular}{lccccc}
\hline Tratamentos & PI & PF & MFSR & FR & REAÇÃO \\
\hline Express & 2300 & $15,91 \mathrm{~b}$ & $9,43 \mathrm{~b}$ & 0,01 & $\mathrm{R}$ \\
Superex & 2300 & $32,81 \mathrm{~b}$ & $7,64 \mathrm{~b}$ & 0,02 & $\mathrm{R}$ \\
Sirius & 2300 & $57,01 \mathrm{~b}$ & $14,05 \mathrm{~b}$ & 0,03 & $\mathrm{R}$ \\
Aquarius & 2300 & $54,88 \mathrm{~b}$ & $13,91 \mathrm{~b}$ & 0,03 & $\mathrm{R}$ \\
Luana & 2300 & $62,68 \mathrm{~b}$ & $14,52 \mathrm{~b}$ & 0,04 & $\mathrm{R}$ \\
Milho (Testemunha) & 2300 & $315,50 \mathrm{a}$ & $53,67 \mathrm{a}$ & 0,14 & $\mathrm{R}$ \\
\hline Teste F (Tratamentos) & - & $16,46^{\star *}$ & $12,74^{\star *}$ & - & - \\
CV\% & - & 75,26 & 62,81 & - & - \\
\hline
\end{tabular}

Médias seguidas de mesma letra na coluna não diferem estatisticamente entre si, pelo teste de Duncan, a $5 \%$ de probabilidade. *Significativo a $5 \%$ de probabilidade; ${ }^{* *}$ significativo a $1 \%$ de probabilidade. Dados transformados em $\mathrm{X}+100$ para análise estatística dos dados. $\mathrm{PI}=$ população inicial de nematoides; MFSR = matéria fresca do sistema 
radicular; $\mathrm{PF}=$ população final; $\mathrm{FR}$ = fator de reprodução; $\mathrm{R}=$ resistente, e $\mathrm{S}=$ suscetível.

O gênero Pratylenchus é responsável por causar lesões nas raízes, pois cavam túneis pelo córtez radicular. Nesta espécie, todos os estágios, exceto os ovos, são livres e podem parasitar as raízes (Nazareno, 2009). A literatura cita que o Pratylenchus brachyurus é um endoparasita migrador, e sua reprodução dá-se por partenogênese, podendo sobreviver de um ciclo para outro do abacaxizeiro, na ausência completa de qualquer tipo de hospedeiro, apenas em função de restos de raízes no solo (Ritzinger \& Costa, 2004).

As gramíneas (milho, sorgo) são consideradas como boas hospedeiras de Pratylenchus brachyurus, permitindo sua reprodução, embora a maioria delas apresente elevada tolerância, exceto sob elevada infestação (Asmus \& Inomoto, 2007).

Da mesma maneira, Santos et al. (2012), ao estudarem a suscetibilidade de híbridos de milho a outra espécie do gênero (Pratylenchus zeae), relataram que tanto no solo quanto nas raízes o número médio de espécimes do nematoide foi baixo, e o FR de todos os materiais testados foi inferior a 1 .

O melhoramento genético vegetal para resistência a espécies de Pratylenchus é consideravelmente difícil, pois são em geral polífagos e relativamente pouco especializados, de hábito endoparasita e migrador, não se fixando à planta hospedeira; assim sendo, o método mais promissor para o controle é a sucessão com culturas não hospedeiras (Goulart, 2008).

\section{Conclusões}

As cinco variedades de cebola estudadas e as testemunhas (berinjela e milho) apresentaram fator de reprodução inferior ( $F R<1)$, demonstrando-se resistentes ao ataque dos gêneros Meloidogyne javanica e Pratylenchus brachyurus.

\section{Referências}

Asmus GL, Inomoto MM (2007) Manejo de nematoides. In: Freire, E. C. (Ed.). Algodão no cerrado do Brasil. 1.ABRAPA, p.551-580.

Castro Neto ER, Toscano LC (2013) Diagnose e manejo de hortas infectadas por nematoides em Cassilândia-MS. Anais do SEMEX. Disponível em: http://periodicos.uems.br/novo/index.php/semex/article/view/1213/619> (Acesso em: 10 dez. 2014).

Coolen WA, D'herde CJ (1972) A method for the quantitative extraction of nematodes from plant tissue. Ghent: State Nematology and Entomology Research Station, 77p.

Fonseca RG (2012) Comportamento de híbridos de milho, em sucessão a soja, ao nematoide Pratylenchus brachyurus. Universidade Federal de
Lavras (Dissertação de mestrado em Agronomia).

Gava CAT, Tavares SCCH (2007) Doenças. In.: Costa ND, Resende GM (2007) Cultivo da cebola no nordeste. Brasília: Embrapa semi-árido, 90p. (Sistemas de Produção, 3, doi: 1807-0027)

Goulart AMC (2008) Nematóides das lesões radiculares (Gênero Pratylenchus). Disponível em: www.cpac.embrapa.br/download/1449/t> (Acesso em 15 abr. 2014).

Green J, Atkinson HJ (2005) Genetic transformation for nematode resistance in rice, potato and cooking bananas for developing countries. Disponível em: $<$ www.research-4development.info/PDF/Outputs/ RLPSRleaflet1E.pdf> (Acesso em 29 mar. 2014)

Guimarães TM (2012) Multiplicação de nematóides Meloidogyne javanica em plantas invasoras e seu efeito sobre o desenvolvimento do manjericão. Faculdade de Agronomia e Medicina Veterinária (Dissertação de mestrado em Agronomia).

Huang SP (1992) Nematóides que atacam olerícolas e seu controle. Informe Agropecuário, 16:31-36.

Huney RS, Barker KR (1973) A comparison of methods of collecting inocula of meloidogyne spp. Including a new technique. Plant Disease Reporter, 57(12):1025-1028.

Nazareno GG (2009) Utilização da matéria orgânica no controle de nematóides das galhas em alface sob cultivo protegido. Faculdade de Agronomia e Medicina Veterinária (Dissertação de mestrado em Agronomia).

Oostenbrink M (1966) Major characteristic of relation between nematodes and plants. Mededelingen Landbouwhogeschool, 66(4):1-46.

Pereira AM (2006) Identificação e manejo de nematóides da bananeira no leste do Estado do Paraná. Universidade Estadual do Paraná (Dissertação de mestrado em Produção Vegetal).

Pinheiro JB, Carvalho ADF, Pereira RB, Rodrigues CS (2013) Ocorrência e manejo de nematóides na cultura do jiló e berinjela. Brasília: Embrapa,, 8 p. (Embrapa. Circular Técnica, 125).

Pinheiro JB, Carvalho ADF, Pereira RB, Rodrigues CS (2014) Nematóides na cultura do alho e da cebola. Brasília: Embrapa, 8 p. (Embrapa. Circular Técnica, 130).

Ritzinger CHSP, Costa DC (2004) Nematóide das lesões (Pratylenchus spp.) em abacaxizeiro. Abacaxi 
em foco. Vol.31. Cruz das Almas. Disponível em:< http://www.cnpmf.embrapa.br/publicacoes/produto_e m_foco/abacaxi_31.pdf> (Acesso em 10 abr. 2014). Santos JF, Fontanella M, Faria MV, Faria CR, Marcondes MM, Giaretta RD (2012) Avaliação da reação de diferentes híbridos de milho a Pratylenchus zeae. Congresso Nacional de Milho e Sorgo, XXIX, Águas de Lindóia, agosto de 2012.

Southey JR (1970) Laboratory methods for work with plant and soil nematodes. $5^{\text {th }}$ Ed. London UK. Ministry Of Agriculture Fisheries and Food, 148p.
Wordell Filho JA (2006) Manejo fitossanitário na cultura da cebola. 1. Ed. Florianópolis: Epagri, 226p.

Rosa JMO; Westerich JN; Wilcken SRS. 2013. Nematoides das Galhas em Áreas de Cultivo de Olerícolas no estado de São Paulo. Nematologia Brasileira 37: 15-19. 